\title{
Retrospective Histopathological Analysis of Cervical Cancer in a Tertiary Care Center
}

\author{
Thangaraj Priya ${ }^{1}$, Balakrishnan Indumati ${ }^{2}$ \\ 1, 2 Department of Pathology, [KAPV] Government Medical College, Trichy, Tamil Nadu, India.
}

\section{ABSTRACT}

\section{BACKGROUND}

Cervical cancer is the third most common cancer among females worldwide. Abnormal vaginal bleeding is the most common presenting complaint in these patients. Some patients remain asymptomatic even in the advanced stages of the disease. Surgery is the treatment of choice in early stages of the disease. Radiotherapy alone or combined with chemotherapy is the treatment in advanced stages of diseases.

\section{METHODS}

This is a retrospective study of various histopathological patterns of cervical neoplasms over a period of 3 years (January 2017 - December 2019). Various histopathological patterns were correlated with clinical presentations and demographic patterns.

\section{RESULTS}

A total of 344 gynaecological malignancies were reported in our study period. Cancer cervix was the most common (238 cases, $69.18 \%$ ). There was a progressive increase in the number of cancer cervix cases from 55 in 2017 to 84 in 2019. In our study, age group of patients ranged from 25 to 82 years and the mean age of presentation was 57.4 years. A high standard deviation of 15.3 was observed. $71.1 \%$ (170 cases) of the patients presented with history of bleeding irregularities followed by growth $(17.3$ $\%, 41$ cases). Squamous cell carcinoma (97.2 \%) was the most common neoplasm with varying subtypes. 6 cases of adenocarcinoma were also reported in our study.

\section{CONCLUSIONS}

Histomorphology remains the mainstay of diagnosis of cervical cancer. Colposcopy guided biopsy is the preferred course of management to definitely rule out or diagnose neoplasia. Histopathological patterns need to be subtyped along with ancillary techniques such as special stains, immunohistochemistry and molecular studies. The main reason behind this is, the treatment modalities and prognosis varies with each subtype. Also, national level cancer program is the need of the hour and should include human papilloma virus vaccine in the immunization schedule for young girls.

\section{KEY WORDS}

Squamous Cell Carcinoma, Cervical Cancer, Post-Menopausal Bleeding, HPV Vaccine, Histomorphological Patterns
Corresponding Author: Dr. Balakrishnan Indumati, Door No. F-16, Royal Denizen Apartment, Pattabiraman Street, Thennnur - 620017, Trichy, Tamil Nadu, India.

E-mail: drpriyajai@gmail.com

DOI: $10.14260 /$ jemds/2020/773

How to Cite This Article:

Priya T, Indumati B. Retrospective histopathological analysis of cervical cancer in a tertiary care center. J Evolution Med Dent Sci 2020;9(47):3523-3527, DOI: $10.14260 /$ jemds/2020/773

Submission 17-06-2020,

Peer Review 08-10-2020,

Acceptance 15-10-2020,

Published 23-11-2020.

Copyright (C) 2020 Thangaraj Priya et al. This is an open access article distributed under Creative Commons Attribution License [Attribution 4.0 International (CC BY 4.0)] 


\section{BACKGROUND}

Cancer cervix is the third most common cancer among women worldwide after breast and lung cancer. ${ }^{1}$ The introduction of HPV virus vaccination programs in the adolescent females in the developed countries have widened the incidence gap between the developed and developing countries. ${ }^{2}$ The mortality rate of cervical cancer is higher in developing countries and they constitute almost $80 \%$ of the total. India constitutes $15.2 \%$ of total cervical cancer deaths in the world. ${ }^{3}$ The natural history of progression from mild dysplasia to cancer cervix is around 10 to 20 years and this provides the rationale for screening. 4 Thus cancer cervix is an early preventable disease. In India 96,922 new cases of cervical cancer are detected every year. ${ }^{5}$ In South India carcinoma cervix is the commonest malignant neoplasm in females. The prevalence of the disease is more in low socioeconomic status. The reason being lack of hygiene and periodical health checkups due to budgetary reasons. Due to expensive HPV vaccine and limitations of cytology based screening programs, disability and death from cancer cervix are high in developing countries which includes India. ${ }^{6}$

Persistent HPV infection is the predominant risk factor of cancer cervix. Risk factors include multiple sex partners, sexual promiscuity, early sexual intercourse, cigarette smoking, multiple pregnancies, OCP (Oral Contraceptive Pills) use and most importantly HPV. Human papilloma virus serves as the etiological factor for many benign and malignant neoplasms of cervix ranging from condyloma acuminata to invasive carcinoma. The infection is transmitted by venereal route and has the propensity for the metaplastic squamous epithelium. Majority of females have self-resolving HPV infection which does not evolve into cancer cervix. Around 10 $\%$ develop persistent infections. This subset have a higher risk of developing cervical cancer. Research analysis have proved that HPV infection is associated with $80 \%$ of cancer cervix. ${ }^{7}$

Postmenopausal bleeding is the most common presenting complaint of these patients. This should be evaluated by colposcopy (VIA / VILI tests), Papanicolaou smear and subsequently cervical biopsy. Patients with abnormal Papanicalaou smear findings have better prognostic outcome. The reason being early diagnosis of the lesion. On an average, a women in $4^{\text {th }}$ decade has $2 \%$ chance of developing malignant cervical neoplasm. This pre and postmenopausal age group constitute the major working population. Cervical cancer not only contributes to mortality, but also it has major impact on socioeconomic status of their families. ${ }^{8}$ Pap smear is a vital screening tool. But it has limited sensitivity between $47 \%$ and $62 \%$. It has disadvantage of subjective interpretation of the results. ${ }^{9}$ The prognosis mainly depends on the clinical stage of the cancer at the time of evaluation. Five year survival rate for stage I of invasive cancer is $92 \%$. The 5 year survival rate of stage III and IV are $25 \%$ and $15 \%$ respectively. The single best gold standard method for the diagnosis of cervical cancer is systematic histopathological examination of cervical biopsies. ${ }^{10}$ Among the varying subtypes, adenocarcinoma, small cell carcinoma, clear cell carcinoma and sarcoma have poor prognosis.

This retrospective study analysis was undertaken with reference to presenting complaints, demographic patterns, morphological features including gross and microscopic features of the study population.

\section{METHODS}

A retrospective study of biopsy specimens of cervix and hysterectomy specimens received in our Pathology Department, KAPV Govt Medical College, Trichy from January 2017 to December 2019 were included in our study. Patient's data comprising of age, presenting complaints, clinical findings, clinical staging, gross and microscopic findings were obtained from the records. All diagnosed cases histologically showing cervical neoplasm in the biopsies and hysterectomy specimens were included in the study. Non neoplastic lesions including inflammation and preneoplastic lesions were excluded. The specimens were examined grossly. Bits taken were fixed in $10 \%$ buffered formalin overnight. The biopsy specimens were processed completely. Multiple sections were taken from hysterectomy specimen. The tissue sections were processed in tissue processor (Leica), paraffin embedded and sections of $3-4$ micron thickness were cut using rotary microtome (Leica). The sections were stained with hematoxylin and eosin stain. Detailed Histopathological analysis and staging was performed. ${ }^{6}$

\section{Statistical Analysis}

Data was analyzed by descriptive analysis. Results were expressed in percentages.

\section{RESULTS}

A total of 344 gynaecological malignancies were reported during our study period out of which cervical malignancies constitute (69.1\%) 238 cases. The present study included 224 biopsies and 14 hysterectomy specimens. The age group of malignancies varied from 20 years to 80 years. Among 238 cases studied, maximum number of cases 75 (31.5\%) belonged to the age group of 51 - 60 yrs. 65 (27.3\%) patients were in the age group of 41 - 50 years, 19 patients (7.98\%) cases were reported in the age group of $31-40 \mathrm{yrs}$. age group. $16(6.72 \%)$ cases in $71-80$ years, $(1.68 \%)$ patients in $21-30$ years and only 3 patients (1.26\%) in 81 - 90 years age group. (Table 1)

\begin{tabular}{|ccc|}
\hline Age (in Years) & No. of Cases & Percentage \\
$21-30$ & 4 & $1.68 \%$ \\
$31-40$ & 19 & $7.98 \%$ \\
$41-50$ & 65 & $27.31 \%$ \\
$51-60$ & 75 & $31.51 \%$ \\
$61-70$ & 56 & $23.52 \%$ \\
$71-80$ & 16 & $6.72 \%$ \\
$81-90$ & 3 & $1.26 \%$ \\
\hline \multicolumn{3}{|c|}{ Table 1. Age Distribution of Malignancy } \\
\hline
\end{tabular}

The mean age of presentation of neoplastic lesion is 57.4 years and a high standard deviation of 15.3 was observed. Youngest patient was 25 years of age and oldest was 82 year old. The mean age was not significantly different for different histological sub types of squamous cell carcinoma with majority being postmenopausal. (Table 4 )

The majority of the patients, 170 cases $(71.7 \%)$ presented with history of bleeding irregularities such as postmenopausal bleeding, menorrhagia, post coital bleeding and 
intermenstrual spotting. This was followed by complaints of growth in 41 cases (17.3\%). 19 cases (7.9\%) presented with pain abdomen and 8 cases (3.1\%) presented with white discharge and itching. (Table 2)

\begin{tabular}{|cccc|}
\hline Sl. No. & Clinical Presentation & No. of Cases & Percentage \\
1. & Bleeding P / V & 170 & $71.7 \%$ \\
2. & Growth & 41 & $17.3 \%$ \\
3. & Pain Abdomen & 19 & $7.9 \%$ \\
4. & White Discharge & 8 & $3.1 \%$ \\
\hline \multicolumn{3}{|c|}{ Table 2. Clinical Presentation of Malignancy } \\
\hline
\end{tabular}

The most common malignancy was squamous cell carcinoma (88.1\%) among which moderately differentiated squamous cell carcinoma comprised (73.1\%) followed by well differentiated squamous cell carcinoma (11.3\%) and poorly differentiated (3.7\%). (Table 3). 15 cases of papillary variant, 4 cases of adenosquamous and 3 cases of basaloid variant was reported.

\begin{tabular}{|cccc|}
\hline Sl. No. & Various Histomorphological Variants & No. & $\%$ \\
1. & Well Differentiated Squamous Cell Carcinoma & 27 & $11.3 \%$ \\
2. & Moderately Differentiated Squamous Cell Carcinoma & 174 & $73.1 \%$ \\
3. & Poorly Differentiated Squamous Cell Carcinoma & 9 & $3.7 \%$ \\
4. & Papillary Squamous Cell Carcinoma & 15 & $6.3 \%$ \\
5. & Adenosquamous Variant of Squamous Cell Carcinoma & 4 & $1.6 \%$ \\
6. & Basaloid Variant of Squamous Cell Carcinoma & 3 & $1.2 \%$ \\
7. & Adenocarcinoma & 6 & $2.5 \%$ \\
\hline \multicolumn{5}{|c|}{ Table 3. Different Variants of Carcinoma } \\
\hline
\end{tabular}

6 cases of adenocarcinoma were reported. The mean age of presentation of adenocarcinoma was $58.7 \%$. The endocervical variant was more common. 1 case was reported as clear cell variant.

According to the International Federation of Gynaecology and Obstetrics (FIGO) staging of patients included in our study, most common presentation was in stage II B. Only few cases were amenable to early treatment and better prognosis category, while cases presenting with distant metastasis and worst prognosis category belonged to older age.

\begin{tabular}{|ccccc|}
\hline Studies (Place) & Time Period & $\begin{array}{c}\text { Age in } \\
\text { Years }\end{array}$ & $\begin{array}{c}\text { Peak } \\
\text { Decade }\end{array}$ & $\begin{array}{c}\text { Mean + } \\
\text { S.D }\end{array}$ \\
Olu-Eddo et al, ${ }^{19}$ Benin, Africa & $1987-2006$ & $15-90$ & 5 th & $50.4+13.5$ \\
Okoyo $^{20}$ Nigeria, Africa) & $2000-2009$ & $18-89$ & 5 th & $51.5+12.8$ \\
${\text { Pathak et al }{ }^{11} \text { Nepal }}^{2013}$ & $24-92$ & 5 th & 42.5 \\
Present Study & $\begin{array}{c}2017-2019(3 \\
\text { years })\end{array}$ & $25-83$ & 5 th & $57.4+15.33$ \\
\hline \multicolumn{2}{|c|}{ Table 4. Comparison of Age Parameters with Other Studies } \\
\hline
\end{tabular}

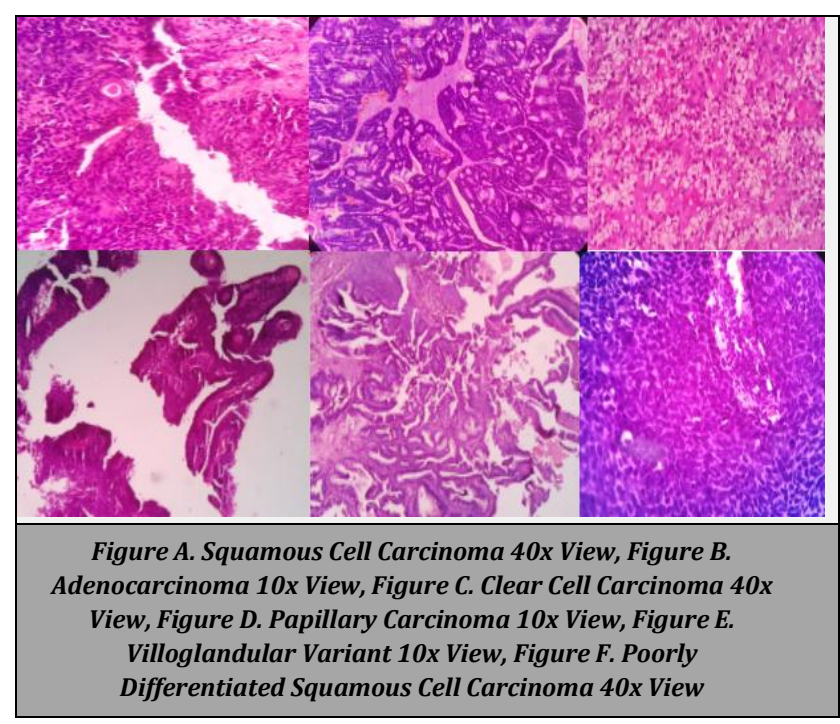

\section{DISCUSSION}

Cervical cancer is one of the leading causes of morbidity and mortality in women worldwide. 4,93,000 new cases and 2,74,000 deaths have been reported each year. The patients are asymptomatic in early stages. Symptomatic patients in the due course of the disease present commonly with vaginal growth, contact bleeding, dyspareunia and discharge per vagina. Stage III and IV cervical cancer patient's complaint of loss of weight, appetite, fatigue, pelvic pain, back pain, heavy bleeding P / V and bone fractures in case of metastasis. Our study shows bleeding per vagina as the most common symptom as seen in literature. ${ }^{11}$

Our study revealed that cancer cervix is still the predominant gynaecological malignancy in our institution (69.18\%). This pattern follows known trends in our country. ${ }^{12}$

Western literature reports have claimed that adenocarcinoma cervix occur in younger age group and a rise of proportion as high as (18.5 - $27 \%$ ) of cases. ${ }^{13}$

But in our study the mean age of diagnosis of both adenocarcinoma and squamous cell carcinoma was similar that is 58.7 years and 57.4 years respectively.

The reason for this discrepancy may be, in western countries effective screening programs are in place and invasive squamous cell carcinoma is in its decreasing trend as the pre invasive lesions are easily detected and treated, whereas adenocarcinoma, being endocervical is less amenable to screening, hence the incidence is on rise.

In our study patients' age ranged from 25 years to 83 years. The mean age of presentation is 58.7 years. Bleeding irregularities was the most frequently reported presenting complaint which is similar to the studies done by Mostafa MG et al,10 Shruthi et al, ${ }^{14}$ Dasetal. ${ }^{15}$

Radical Hysterectomy specimens constituted $5.9 \%$ and cervical biopsies accounted for $94.1 \%$ in this study. The reason for less number of hysterectomy specimens is due to referral of patients diagnosed as carcinoma for radiotherapy in higher centres.

The total number of cases were in increasing trend which reflects the general population. The need of the hour is frequent and effective PAP smear screening program in our country. HPV vaccination programs should be included in the universal immunization program of India. Due to expensive HPV vaccine and limitations of cytology screening program the death and disability are high in developing countries including India. ${ }^{16}$ WHO recommends that every women should be screened at least once in her lifetime at 40 years. The frequency of screening should be increased to "once every 10 years" and then once every 5 years for women 35 - 55 years of age. ${ }^{17}$ Community programs are essential to educate parents, teachers, adolescents about human papilloma virus infection, cervical cancer and preventable measures such as vaccine. ${ }^{18}$

Histopathological study of specimens showed squamous cell carcinoma to be the predominant cancer (97.2\%). Our study showed varying subtypes of squamous cell carcinoma. The well differentiated verrucous carcinoma, warty type being the exception. This is in concordance with studies of OluEddoet al. ${ }^{19}$ Okoyo ${ }^{20}$ Abudu et al. ${ }^{21}$

In our study 15 cases (6.3\%) of papillary squamous cell carcinoma was reported (2.5\%). The papillary squamo transitional cell carcinoma of cervix is an aggressive tumour 
and it has to be distinguished from the common benign papillary lessons of the cervix. These tumours are distinct homogenous group that display a morphological spectrum.

6 cases of adenocarcinoma was reported. Adenocarcinoma should be delineated clearly from squamous cell carcinoma and adeno squamous variants. This is because adenocarcinoma has a high recurrence rate and mostly present in stage III and IV and has a poor prognosis. ${ }^{22}$

1 case of clear cell adenocarcinoma was reported in our study. Clear cell adenocarcinoma is a rare subtype associated with cervical endometriosis and exposure to diethylstilbesterol. Studies have shown a lower 5 year survival rate. This subtype classically presents as endophytic growth and infiltrates deep into the cervix. Hence early diagnosis helps in better treatment of these patients. ${ }^{23}$

4 cases (1.6\%) of adenosquamous cell carcinoma was reported with age distribution being (40 - 60 years). This is similar to study done by Alfsenetal. ${ }^{24}$

The mitotic index is a key prognostic factor for behaviour and treatment of cervical cancer. Significantly higher mitotic count is seen in moderately and poorly differentiated squamous cell carcinoma. ${ }^{25}$ In our study, well differentiated squamous cell carcinoma had mitotic count of 4 / $10 \mathrm{HPF}$ whereas poorly differentiated squamous cell carcinoma showed mitotic count of 11 / $10 \mathrm{HPF}$.

In conclusion, clinical presentation and the peak age presentation (51 - 61 years) was similar to most of the studies. Majority of the cases were in stage IIB followed closely by advanced stage (III and IV). This is in concordance with other studies from India. ${ }^{26}$

\section{CONCLUSIONS}

In our study, a wide spectrum of morphological (gross and microscopic) subtypes of carcinoma cervix was diagnosed. Histopathological examination and subtyping remain the basis for clinical management, treatment, prognosis and subsequent follow up of a patient. Our study demonstrates that carcinoma cervix is still the predominant malignancy among gynaec patients in our institution. Above findings stress that the cervical screening procedure should be initiated in an earlier age group who are sexually active. This will reduce the long term morbidity, mortality and socioeconomic burden related with carcinoma cervix.

Data sharing statement provided by the authors is available with the full text of this article at jemds.com.

Financial or other competing interests: None.

Disclosure forms provided by the authors are available with the full text of this article at jemds.com.

\section{REFERENCES}

[1] Park K. Park's text book preventive and social medicine 21 st edn. India: M/S Banarasidas Bhanot 2011.

[2] Moodley M, Moodley J, Kleinschmidt I. Invasive cervical cancer and human immune deficiency virus (HIV) infection: a South African perspective. Int J Gynecol Cancer 2001;11(3):194-7.
[3] Ferlay J, Shin HR, Bray F, et al. Estimates of worldwide burden of cancer in 2008: GLOBOCAN 2008. 2010;127(12):2893-917.

[4] World Health Organisation. Comprehensive cervical cancer control: a guide to essential practice. Geneva: WHO 2006:132-49.

[5] Ferlay J, Soerjomataram I, Ervik M, et al. GLOBOCAN 2012: estimated cancer incidence, mortality and prevalence worldwide in 2012. v1.0 IARC Cancer Base No. 11, 2012.

[6] Tavassoli AF, Devilee P. WHO classification of tumors, pathology and genetics- tumors of the breast \& female genital organs. Lyon, France: IARC Press 2003:259-90.

[7] Chaturvedi AK, Kleinerman RA, Hildeshani A, et al. Second cancers after squamous cell carcinoma and adenocarcinoma of cervix. J Clin Oncol 2009;27(6):96773.

[8] Pradhan B, Pradhan SB, Mital VP. Correlation of PAP smear finding with clinical findings and cervical biopsy. Kathmandu Univ Med J (KUM J) 2007;5(4):461-7.

[9] Shastri SS, Mittra I, Mishra GA, et al. Effect of VIA screening by primary health workers: randomized controlled study in Mumbai, India. J Natl Cancer Inst 2014;106(3):dju009.

[10] Mostafa MG, Srivannaboon S, Rachanawutanon M. Accuracy of cytological findings in abnormal cervical smears by cytohistologic comparison. Indian J Pathol Microbiol 2000;43(1):23-9.

[11] Yang DH, Kim JK, Kim KW, et al. MRI of small cell carcinoma of the uterine cervix with pathologic correlation. AJR Am J Roentgenol 2004;182(5):1255-8.

[12] Cancer Research in ICMR: Achievements in nineties. Indian Council of Medical Research. https://main.icmr.nic.in/sites/default/files/guidelines/c ancer_0.pdf

[13] Anton-Culver H, Bloss JD, Bringman D, et al. Comparison of adenocarcinoma and squamous cell carcinoma of the uterine cervix: a population-based epidemiologic study. Am J Obstet Gynecol 1992;166(5):1507-14.

[14] Shruthi PS, Kalyani R, Kai LJ, et al. Clinicopathological correlation of cervical carcinoma: a tertiary hospital based study. Asian Pac J Cancer Prev 2014;15(4):1671-4.

[15] Das RK. Cancer cervix in Assam. An etiological analysis of 250 cases. J Obstet Gynecol India 1969:11-16.

[16] Miller AB, Chamberlain J, Day NE, et al. Report on a workshop of the UICC project on evaluation of screening for cancer. Int J Cancer 1990;46(5):761-9.

[17] Miller AB. Cervical cancer screening programs: managerial guidelines. Geneva: World Health Organization 1992.

[18] Soares GR, da Vieira RR, Pellizzer EP, et al. Indications for the HPV vaccine in adolescents: a review of the literature. J Infect Public Health 2015;8(2):105-16.

[19] Olu-Eddo AN, Ekanem VJ, Umannah I, et al. A 20 year histopathological study of cancer of the cervix in Nigerians. Nig Q J Hosp Med 2011;21(2):149-53.

[20] Okoye CA. Histopathological pattern of cervical cancer in Benin City, Nigeria. J Med Investig Pract 2014;9:147-50.

[21] Abudu EK, Banjo AA, Izegbu MC, Agboola AO, et al. Histopathological pattern of carcinoma of cervix in Olabisi Onabanjo University Teaching Hospital, Sagamu, Nigeria. NQJHM 2006;16(3):80-4. 
[22] Koeing C, Turniky RP, Kankam CF, et al. Papillary squamotransitional cell carcinoma of the cervix: a report of 32 cases. Am J Surg Pathol 1997;21(8):915-21.

[23] Hiromur T, Tanaka YO, Nishioka T, et al. Clear cell adenocarcinoma of the uterine cervix arising from a background of cervical endometriosis. $\mathrm{Br} \mathrm{J}$ Radiol 2009;82(973):e20-2.

[24] Alfsen GC, Kristensen GB, Skovlund E, et al. Histologic subtype has minor importance for overall survival in patients with adenocarcinoma of the uterine cervix: a population-based study of prognostic factors in 505 patients with nonsquamous cell carcinomas of the cervix. Cancer 2001;92(9):2471-83.

[25] Sagol 0, Yorukoglu K, Sagol S, et al. Apoptotic and mitotic index in squamous cell carcinoma and premalignant lesions of the uterine cervix. Indian J Surg Pathol 1999;7(3):155-60.

[26] Nandakumar A, Anantha N, Venugopal TC. Incidence, mortality and survival in cancer of the cervix in Bangalore, India. Br J Cancer 1995;71(6):1348-52. 